\title{
C-banding Patterns in Eighteen Taxa of the Genus Paris sensu Li, Liliaceae
}

\author{
Junko Miyamoto ${ }^{1}$, Siro Kurita ${ }^{1}$, Gu Zhijian ${ }^{2}$ and Li Hen ${ }^{2}$ \\ $\downarrow$ Department of Biology, Faculty of Science, Chiba University, Japan \\ 2 Kunming Institute of Botany, Academy of Science of China, Kunming, Yunnan, China
}

Accepted October 31, 1991

Paris is a perennial genus distributed from Europe to the Far East. Most species, however, are restricted to Asia, excepting a European species $P$. quadrifolia Linnaeus and a Caucasian species $P$. incompleta M.-Bieberstein. Hara (1969) studied morphological variation in seven species: $P$. delavayi Franchet; $P$. incompleta M.-Bieberstein; $P$. japonica (Franch. et Sav.) Franchet; $P$. polyphylla Smith; $P$. quadrifolia Linnaeus; $P$. tetraphylla A. Gray; and $P$. verticillata M.-Bieberstein. Takhtajan (1983) founded a new genus Daiswa for all taxa of $P$. polyphylla complex, but Li (1988) degraded this to the subgeneric level. The historical background of Paris taxonomy and the synonymy of each taxon were summarized by Mitchell $(1987,1988)$.

Karyomorphological studies on Japanese species were carried out by various authors (Gotoh 1933, Haga 1934, 1942, Hara 1969, Kayano 1961, Kurabayashi 1952, Kurabayashi and Samejima 1953, Miyamoto and Kurita 1990, Miyamoto et al. 1991, Noda 1963, Stow 1953, Suzuki and Yoshimura 1986). The standard chromosome numbers reported by these authors are $2 \mathrm{n}=10(2 \mathrm{X})$ in $P$. teteraphylla and $P$. verticillata and $2 \mathrm{n}=40(8 \mathrm{X})$ in $P$. japonica. The only European species, $P$. quadrifolia, was examined by many authors (Tischler 1934, Gotoh 1937, Geitler 1938, Darlington 1941, Löve and Löve 1944, Pólya 1950, Skaliñska et al. 1957, Sorsa, 1962, Laane and Lie 1985, Lavrenko and Serditov 1987, Malakhova et al. 1979) and found to be $2 n=20(4 X)$. Recently, the karyotype of sixteen Chinese taxa were revealed by some authors (Gu 1984, Gu and $\mathrm{Na} \mathrm{1986,} \mathrm{Gu}$ and $\mathrm{Li} \mathrm{1988,} \mathrm{Hong} \mathrm{and} \mathrm{Zhu} \mathrm{1987).} \mathrm{Except}$ the $4 \mathrm{X}$ cytotypes in $P$. axialis, $P$. delavayi and $P$. verticillata, all Chinese plants examined were $2 \mathrm{X}$ and some of them carried a few supernumerary chromosomes. According to Li et al. (1988), there are two types within the basic karyotype. The so-called "tropical type" consists of six metacentric chromosomes and four telocentric chromosomes, while the "temperate type" consists of six metacentrics with subterocentrics and telocentrics.

On the other hand, Darlington and La Cour (1938), Kurabayashi (1952) and Noda (1963) reported the heterochromatic differential reactivity of some chromosomal distal segments under conditions of chill or chemical stress in three Paris species. More recently, C-banding positive heterochromatin blocks were detected in $P$. tetraphylla and $P$. verticillata, and some of these were shown to be species-specific C-bands (Miyamoto and Kurita 1990, Miyamoto et al. 1991).

In the present study, we investigate the C-banding patterns of eighteen taxa of the genus with the BSG method and discuss similarities and dissimilarities in the patterns of the various taxa.

Materials and methods

Three Japanese species, $P$. japonica, $P$. verticillata and $P$. tetraphylla, were collected from their natural habitats. Three plants of $P$. polyphylla var. polyphylla were collected in Formosa, 
Table 1. Taxa, localities, and number of plants examined

\begin{tabular}{|c|c|c|c|c|}
\hline \multicolumn{2}{|c|}{ Taxon } & \multirow{2}{*}{$\frac{\text { Code }}{\text { (CR) }}$} & \multirow{2}{*}{$\frac{\text { Locality }}{\text { Lingyun, Guangxi, China }}$} & \multirow{2}{*}{$\begin{array}{c}\begin{array}{c}\text { number of } \\
\text { plant examined }\end{array} \\
2\end{array}$} \\
\hline 1 & P. cronquistii & & & \\
\hline 2 & P. vietnamensis & (VI) & Pingbian, Yunnan, China & 3 \\
\hline 3 & P. delavayi & (DE) & Yiliang, Yunnan, China & 2 \\
\hline 4 & P. polyphylla var. polyphylla & (PO) & Formosana & 3 \\
\hline & & & $\begin{array}{l}\text { unknown } \\
\text { Yiliang, Yunnan. China }\end{array}$ & $\begin{array}{l}2 \\
2\end{array}$ \\
\hline 5 & P. polyphylla var. stenophylla & (ST) & Yiliang, Yunnan, China & 2 \\
\hline 6 & $\begin{array}{l}\text { P. polyphylla var. stenophylla } \\
\text { f. latifolia }\end{array}$ & (LA) & Hubei, China & 2 \\
\hline 7 & P. polyphylla var. yunnanensis & (YU) & Louping, Yunnan, China & 2 \\
\hline 8 & $\begin{array}{l}\text { P. polyphylla var. pseudothibetica } \\
\text { f. macrosepala }\end{array}$ & (PS) & Yiliang, Yunnan, China & 2 \\
\hline 9 & P. mairei & (MA) & Dali, Yunnan, China & 2 \\
\hline 10 & P. Iuquanensis & $(L U)$ & Luquan, Yunna, China & 3 \\
\hline 11 & P. fargesii & (FA) & Sangzhi, Hunan, China & 1 \\
\hline 12 & P. thibetica & (TH) & Dali, Yunnan, China & 1 \\
\hline 13 & P. axialis & $(\mathrm{AX})$ & Yiliang, Yunnan, China & 2 \\
\hline 14 & P. forrestii & (FO) & Tengchong, Yunnan, China & 1 \\
\hline 15 & $P$. vaniotii & (VA) & Huishui, Guizhou, China & 1 \\
\hline 16 & $P . P$. verticillata & (VE) & Hokkaido and Honshu, Japan & 160 \\
\hline 17 & P. tetraphylla & (TE) & $\begin{array}{l}\text { Hokkaido, Honshu, Shikoku, and } \\
\text { Kyushu, Japan }\end{array}$ & 692 \\
\hline 18 & P. japonica & $(\mathrm{JA})$ & Honshu, Japan & 25 \\
\hline
\end{tabular}

while two of this variety were from mainland China. These four taxa were cultivated in the experimental garden at Chiba Universtiy, Japan. The rest of the materials were collected in mainland China and cultivated in the garden at Kunming Institute of Botany, Yunnan, China. The taxa, localities and number of plants examined are summarized in Table 1.

Each plant was examined with the C-banding BSG method following Miyamoto and Kurita (1990).

Five enlarged microphotographs $(\times 1000)$ of well-spread metaphase plates per plant were selected, whereupon absolute and average length of all segments of the C-banded chromosome were measured and calculated automatically with the chromosome image analyzing system, CHIAS. Details of the system and an outline of the procedure of image analysis were reported in a previous paper (Miyamoto et al. 1991).

Accurate idiograms were drawn on the basis of average length as determined by CHIAS and a restrictive number was given to each distinguishable segment of every chromosome. Then codes were used to describe the segments. For example, a segment numbered 2 on the short arm (p) of a large metacentric chromosome (1M) was described as $1 \mathrm{Mp} 2$, and a segment numbered 3 on the long arm (q) of a shorter acrocentric chromosome (sA) as sAq3. Abbreviations $1 \mathrm{M}, \mathrm{mM}, \mathrm{sM} \mathrm{sbM}, 1 \mathrm{~A}$, and $\mathrm{sA}$ in the codes or figures represent, respectively, large metacentric, medium size metacentric, small metacentric, submetacentric, longer acrocentric, and shorter acrocentric chromosomes. The percentage of $\mathrm{C}$-banding positive heterochromatin volume to total chromatin was calculated on the basis of data obtained using CHIAS.

\section{Observations}

The C-banded metaphase or prometaphase chromosomes of the eighteen taxa examined are shown in Figs. 1 to 18. Some C-banding positive heterochromatic segments were detected on most of the cromosomes of every taxa examined. The average length $(\mu \mathrm{m})$ of each seg- 
ment is summarized in Table 2. An idogram of the genome of each taxon was drawn on the basis of the data derived from CHIAS and arranged in tandem (Fig. 19). In this figure, the uppermost chromosome is $1 \mathrm{M}$, the second $\mathrm{mM}$, the third $\mathrm{sM}$ or $\mathrm{sbM}$, and the fourth and lewest A or sbM. Results obtained in each taxon are specified.

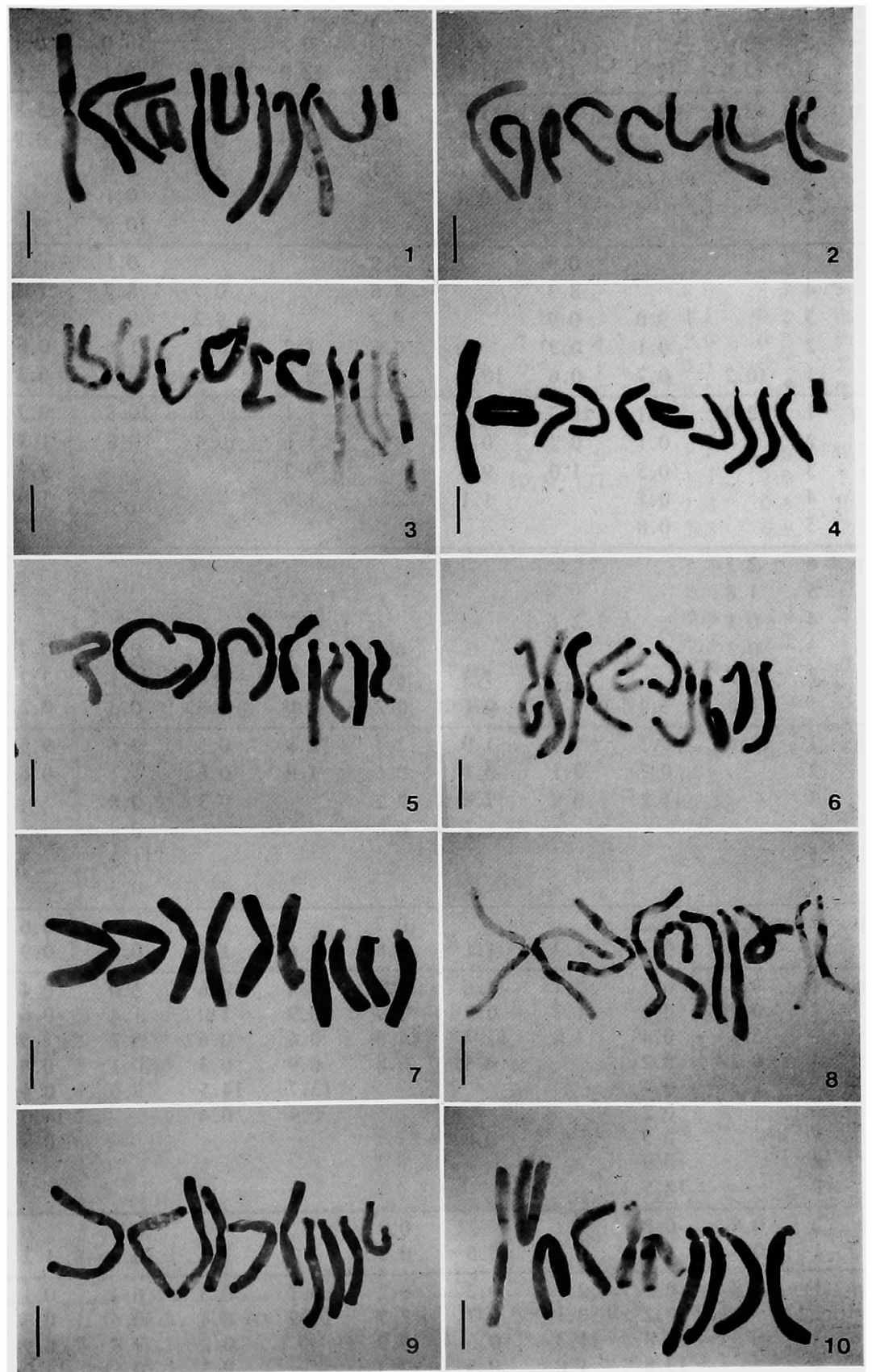

Figs. 1-10. The C-banded chromosome complements of 18 taxa examined. $1, P$. cronqistii $2, P$. vietnamensis $3, P$. delavayi $4, P$. polyphylla var. polyphylla $5, P$. polyphylla var. stenophylla $6, P$. polyphylla var. stenophylla f. latifolia $7, P$. polyphylla var. yuunanensis $8, P$. polyphylla var. pseudothibetica f. macrocepala $9, P$. mairei $10, P$. luquanensis. 
Table 2-1. Mean length $(\mu \mathrm{m})$ of every segment on each chromosome in the genomes of 18 taxa examined

\begin{tabular}{|c|c|c|c|c|c|c|c|c|c|c|c|c|}
\hline \multicolumn{3}{|c|}{$\begin{array}{l}\text { Segment } \\
\text { cord }\end{array}$} & CR & VI & $\mathrm{DE}$ & PO & ST & LA & $\mathrm{YU}$ & PS & MA & LU \\
\hline \multirow[t]{9}{*}{$\mathrm{IM}$} & $\mathrm{p}$ & 4 & & & & & & & & & 0.9 & \\
\hline & & 3 & & & & & & & & & 9.6 & 10.2 \\
\hline & & 2 & & & 11.3 & 0.6 & 0.3 & 0.2 & 1.2 & 13.0 & 0.1 & 0.2 \\
\hline & & 1 & 12.0 & 12.3 & 1.2 & 11.3 & 11.6 & 12.0 & 11.8 & 0.1 & 2.6 & 2.2 \\
\hline & $q$ & 1 & 13.4 & 14.2 & 14.5 & 1.3 & 6.2 & 0.6 & 0.9 & 0.7 & 13.8 & 4.3 \\
\hline & & 2 & 0.5 & & & 0.2 & 0.3 & 13.0 & 0.1 & 0.3 & 0.9 & 0.5 \\
\hline & & 3 & 0.8 & & & 12.1 & 8.1 & 0.8 & 5.2 & 2.6 & & 9.6 \\
\hline & & 4 & & & & 0.4 & & & & 0.1 & & \\
\hline & & 5 & & & & & & & & 10.6 & & \\
\hline \multirow[t]{10}{*}{$\mathrm{mM}$} & p & 5 & & & 0.9 & & 0.9 & & & 0.1 & & \\
\hline & & 4 & & & 8.3 & & 8.6 & & 0.7 & 8.7 & 1.3 & \\
\hline & & 3 & & 9.0 & 0.9 & & 0.2 & & 9.2 & 0.1 & 2.5 & \\
\hline & & 2 & & 0.1 & 0.3 & & 0.6 & 1.2 & 0.1 & 1.6 & 0.6 & 0.9 \\
\hline & & 1 & 10.2 & 0.7 & 0.6 & 10.6 & 0.3 & 9.6 & 0.6 & 0.2 & 6.3 & 9.9 \\
\hline & $q$ & 1 & 12.4 & 0.1 & 10.7 & 1.2 & 11.1 & 1.1 & 11.6 & 10.8 & 0.7 & 2.0 \\
\hline & & 2 & & 0.1 & 0.2 & 0.6 & 0.6 & 1.6 & 0.4 & 0.6 & 1.1 & 0.1 \\
\hline & & 3 & & 10.5 & 1.0 & 9.0 & & 9.2 & & & 9.7 & 9.4 \\
\hline & & 4 & & 0.1 & & 1.1 & & 1.0 & & & 1.0 & 0.4 \\
\hline & & 5 & & 0.8 & & & & & & & & \\
\hline \multirow[t]{12}{*}{ sM } & $p$ & 6 & 2.5 & & & & & & & & & \\
\hline & & 5 & 1.8 & & & & & & & & & \\
\hline & & 4 & 0.1 & & 2.1 & & & 0.7 & & & & \\
\hline & & 3 & 0.3 & & 3.1 & & 0.9 & 5.1 & & 2.0 & 0.7 & \\
\hline & & 2 & 0.2 & & 0.2 & 7.5 & 6.6 & 0.9 & 0.6 & 5.1 & 7.7 & 0.8 \\
\hline & & 1 & 1.0 & 7.4 & 1.2 & 0.1 & 0.2 & 1.0 & 7.0 & 0.3 & 0.2 & 7.3 \\
\hline & $q$ & 1 & 13.5 & 0.2 & 9.8 & 1.0 & 1.1 & 8.8 & 0.5 & 0.6 & 9.5 & 0.7 \\
\hline & & 2 & & 0.7 & 0.1 & 0.1 & 0.6 & 1.0 & 0.6 & 1.1 & 0.6 & 0.8 \\
\hline & & 3 & & 11.2 & 0.9 & 7.6 & 7.2 & & 9.3 & 0.8 & & 7.6 \\
\hline & & 4 & & & & 1.1 & 0.6 & & & 0.4 & & 0.7 \\
\hline & & 5 & & & & & & & & 11.2 & & \\
\hline & & 6 & & & & & & & & 0.3 & & \\
\hline \multirow[t]{11}{*}{$1 \mathrm{~A}$} & $\mathrm{p}$ & 2 & 0.6 & 1.2 & & & 0.7 & & & 1.0 & 0.6 & 1.1 \\
\hline & & 1 & 1.3 & 0.3 & 1.3 & 1.1 & 0.6 & 1.6 & 1.6 & 0.6 & 0.9 & 1.0 \\
\hline & $q$ & 1 & 0.6 & 0.1 & 2.1 & 2.6 & 1.7 & 0.4 & 0.6 & 3.0 & 0.4 & 0.7 \\
\hline & & 2 & 0.4 & 0.2 & 1.3 & 0.2 & 0.9 & 0.9 & 1.0 & 1.4 & 0.6 & 1.1 \\
\hline & & 3 & 15.6 & 0.4 & 14.0 & 13.7 & 14.6 & 0.6 & 0.6 & 5.2 & 1.0 & 0.6 \\
\hline & & 4 & 0.2 & 0.2 & & 0.8 & 0.8 & 0.9 & 0.3 & 0.1 & 0.6 & 1.3 \\
\hline & & 5 & 1.3 & 0.4 & & & & 13.7 & 14.5 & 9.6 & 0.4 & 13.7 \\
\hline & & 6 & & 0.2 & & & & 0.9 & 0.4 & & 14.0 & 0.8 \\
\hline & & 7 & & 0.5 & & & & & & & 0.9 & 0.6 \\
\hline & & 8 & & 0.9 & & & & & & & & \\
\hline & & 9 & & 14.5 & & & & & & & & \\
\hline \multirow[t]{10}{*}{$\mathrm{sA}$} & $\mathrm{p}$ & 2 & 0.8 & 0.8 & & & 0.7 & & & 0.7 & & \\
\hline & & 1 & 0.6 & 1.0 & 0.7 & 0.6 & 0.3 & 1.2 & 1.1 & 0.3 & 1.2 & 1.1 \\
\hline & $q$ & 1 & 16.8 & 0.7 & 2.7 & 0.2 & 0.2 & 0.7 & 0.3 & 6.4 & 0.1 & 0.6 \\
\hline & & 2 & & 0.2 & 0.1 & 0.7 & 2.7 & 15.9 & 0.4 & 0.6 & 0.7 & 5.2 \\
\hline & & 3 & & 0.8 & 11.3 & 0.6 & 0.9 & & 0.2 & 9.8 & 0.9 & 0.4 \\
\hline & & 4 & & 13.8 & 1.0 & 0.3 & 12.3 & & 0.3 & 0.1 & 14.0 & 0.2 \\
\hline & & 5 & & & 1.3 & 14.3 & 0.8 & & 14.6 & 2.6 & 0.6 & 0.3 \\
\hline & & 6 & & & & 0.6 & & & & 0.3 & & 0.4 \\
\hline & & 7 & & & & & & & & & & 10.0 \\
\hline & & 8 & & & & & & & & & & 0.6 \\
\hline
\end{tabular}


Table 2-2. Mean length $(\mu \mathrm{m})$ of every segment on each chromosome in the genomes of 18 taxa examned

\begin{tabular}{|c|c|c|c|c|c|c|c|c|c|c|c|c|c|}
\hline \multicolumn{3}{|c|}{$\begin{array}{l}\text { Segment } \\
\text { cord }\end{array}$} & \multirow[t]{4}{*}{ FA } & \multirow[t]{5}{*}{ TH } & \multirow[t]{4}{*}{$\mathrm{AX}$} & \multirow[t]{4}{*}{ FO } & \multirow[t]{4}{*}{ VA } & \multirow[t]{4}{*}{ VE } & \multirow[t]{3}{*}{$\mathrm{TE}$} & \multicolumn{4}{|c|}{ JA } \\
\hline \multirow{12}{*}{ IA } & $\mathrm{p}$ & 7 & & & & & & & & 12.2 & & 8.2 & \\
\hline & & 6 & & & & & & & & 1.2 & & 0.4 & \\
\hline & & 5 & & & & & & & & 0.3 & 8.1 & 0.1 & \\
\hline & & 4 & 0.8 & & & & & & & 0.4 & 0.5 & 2.2 & \\
\hline & & 3 & 10.5 & & & & & 13.7 & 13.0 & 0.2 & 0.4 & 0.1 & 8.8 \\
\hline & & 2 & 0.2 & & 0.9 & 1.2 & & 1.3 & 0.4 & 0.3 & 3.7 & 0.1 & 2.2 \\
\hline & & 1 & 1.2 & 12.8 & 12.5 & 13.3 & 13.5 & 0.5 & 0.6 & 0.5 & 0.3 & 0.2 & 0.3 \\
\hline & $q$ & 1 & 14.2 & 14.3 & 15.0 & 14.2 & 14.9 & 0.8 & 0.4 & 0.3 & 3.5 & 0.3 & 0.3 \\
\hline & & 2 & & & & 0.8 & & 1.0 & 0.6 & 0.5 & 1.1 & 0.4 & 4.5 \\
\hline & & 3 & & & & & & 15.7 & 13.7 & 0.3 & 10.2 & 1.2 & 10.0 \\
\hline & & 4 & & & & & & & & 0.4 & & 0.3 & \\
\hline & & 5 & & & & & & & & 13.8 & & 13.1 & \\
\hline \multirow[t]{10}{*}{$\mathrm{mM}$} & $\mathrm{p}$ & 5 & & & & & & & & 6.0 & 8.1 & 5.0 & \\
\hline & & 4 & & & & & & 1.8 & & 0.1 & 0.2 & 0.2 & \\
\hline & & 3 & & & & & & 7.1 & 8.1 & 1.9 & 0.3 & 0.1 & 5.9 \\
\hline & & 2 & 0.8 & & 1.0 & 0.9 & & 0.8 & 1.4 & 0.3 & 0.7 & 2.5 & 1.2 \\
\hline & & 1 & 10.0 & 11.0 & 9.6 & 10.6 & 10.9 & 0.3 & 0.5 & 0.1 & 0.2 & 0.3 & 0.3 \\
\hline & $q$ & 1 & 2.7 & 12.1 & 11.7 & 11.5 & 12.4 & 0.1 & 0.6 & 0.3 & 0.2 & 0.1 & 9.3 \\
\hline & & 2 & 0.7 & & 0.6 & 0.9 & & 0.2 & 0.7 & 1.8 & 1.0 & 0.3 & \\
\hline & & 3 & 7.1 & & & & & 10.8 & 11.0 & 1.1 & 2.0 & 1.1 & \\
\hline & & 4 & 0.9 & & & & & & & 1.2 & 0.6 & 0.2 & \\
\hline & & 5 & & & & & & & & 7.3 & 6.9 & 7.0 & \\
\hline \multirow[t]{10}{*}{$\mathrm{sM}$} & $\mathrm{p}$ & 5 & & & & & & & & 3.7 & & & \\
\hline & & 4 & & & & & & 1.1 & & 0.4 & & & \\
\hline & & 3 & & & & & & 7.1 & 6.7 & 0.5 & 3.4 & 2.8 & 3.5 \\
\hline & & 2 & 1.1 & & 0.8 & 0.9 & 0.6 & 0.2 & 0.1 & 0.3 & 1.2 & 1.1 & 1.4 \\
\hline & & 1 & 7.0 & 8.2 & 7.4 & 6.8 & 7.0 & 0.2 & 0.1 & 0.4 & 0.8 & 0.4 & 0.4 \\
\hline & $q$ & 1 & 1.2 & 10.6 & 10.2 & 10.2 & 10.6 & 0.9 & 0.5 & 0.3 & 0.8 & 0.1 & 0.2 \\
\hline & & 2 & 0.6 & & 0.3 & 0.7 & & 1.1 & 0.3 & 0.7 & 0.8 & 2.1 & 0.9 \\
\hline & & 3 & 8.8 & & & & & 8.7 & 8.2 & 0.4 & 6.5 & 5.8 & 5.8 \\
\hline & & 4 & & & & & & & & 0.8 & & & \\
\hline & & 5 & & & & & & & & 6.4 & & & \\
\hline \multirow[t]{14}{*}{ IA } & $\mathrm{p}$ & 6 & & & & & & 2.0 & 2.2 & & & & \\
\hline & & 5 & & & & & & 1.0 & 0.4 & & & & \\
\hline & & 4 & & & & & & 1.0 & 0.2 & & & & \\
\hline & & 3 & & & & & & 0.8 & 0.8 & & & & \\
\hline & & 2 & & 1.2 & & 0.3 & 0.4 & 0.6 & 0.7 & 1.6 & 0.7 & 1.8 & 0.3 \\
\hline & & 1 & 1.7 & 1.3 & 1.2 & 0.4 & 1.0 & 0.6 & 0.7 & 1.7 & 1.8 & 0.1 & 1.7 \\
\hline & $\mathbf{q}$ & 1 & 1.3 & 17.6 & 17.2 & 0.3 & 1.1 & 15.9 & 1.5 & 0.9 & 1.3 & 0.2 & 0.1 \\
\hline & & 2 & 15.1 & & & 0.4 & 0.8 & & 0.9 & 1.3 & 1.9 & 1.2 & 0.2 \\
\hline & & 3 & 0.5 & & & 1.0 & 14.2 & & 12.2 & 0.2 & 0.1 & 0.2 & 0.1 \\
\hline & & 4 & & & & 0.4 & 0.2 & & & 1.8 & 0.6 & 1.4 & 2.1 \\
\hline & & 5 & & & & 7.8 & 1.4 & & & 9.1 & 0.1 & 0.2 & 0.2 \\
\hline & & 6 & & & & 0.4 & & & & & 0.3 & 0.4 & 8.8 \\
\hline & & 7 & & & & 7.2 & & & & & 7.9 & 8.4 & \\
\hline & & 8 & & & & 0.6 & & & & & & & \\
\hline \multirow[t]{10}{*}{$\mathrm{sA}$} & $\mathrm{p}$ & 3 & & & & & & & & & 1.0 & & \\
\hline & & 2 & 0.6 & & & 0.6 & & & & 0.1 & 0.3 & 0.5 & \\
\hline & & 3 & 0.7 & 0.7 & 0.7 & 0.3 & 1.0 & 2.0 & 2.2 & 1.8 & 0.2 & 1.0 & 1.1 \\
\hline & $q$ & 1 & 0.8 & 17.3 & 15.6 & 14.7 & 0.1 & 14.4 & 0.5 & 0.2 & 0.1 & 0.1 & 0.1 \\
\hline & & 2 & 1.1 & & 0.6 & 1.0 & 15.7 & & 1.7 & 0.1 & 1.5 & 2.8 & 3.0 \\
\hline & & 3 & 0.3 & & & & & & 12.0 & 0.1 & 0.2 & 9.1 & 8.4 \\
\hline & & 4 & 0.1 & & & & & & & 1.2 & 1.0 & & \\
\hline & & 5 & 13.0 & & & & & & & 0.2 & 0.3 & & \\
\hline & & 6 & 0.2 & & & & & & & 0.2 & 0.1 & & \\
\hline & & 7 & 0.8 & & & & & & & 10.1 & 9.0 & & \\
\hline
\end{tabular}


1. P. cronquistii Takhtajan: $[\mathrm{CR}]: 2 \mathrm{n}=2(\mathrm{lM}+\mathrm{mM}+\mathrm{sbM}+1 \mathrm{~A}+\mathrm{sA})+1 \mathrm{~B}$

The IM had a C-band (q2) at the terminal region. The sbM had a thick terminal band (p6) and two thin bands (p2, p4). The IA carried three C-bands, two terminal (p2, q4) and one proximal (q2). Moreover, C-banding positive dots of less than $0.1 \mu \mathrm{m}$ appeared at the extreme terminal region of both arms and the centromeric region of $1 \mathrm{~A}$ and $\mathrm{mM}$. Similar dots were also observed at the terminal region of the long arm of sbM, $1 \mathrm{~A}$ and $\mathrm{sA}$. These dots were detected in all taxa examined. The length of a telocentic supernumerary chromosome, $\mathrm{B}$, was $5.0 \mu \mathrm{m}$ and a small amount of C-banding positive heterochromatin was observeed only at the centromeric region.

2. P. vietnamensis (Takhtajan) Li Hen: [VI]: $2 n=2(1 \mathrm{M}+\mathrm{mM}+\mathrm{sM}+1 \mathrm{~A}+\mathrm{sA})$

The $\mathrm{mM}$ had one terminal (q4) and two proximal $(\mathrm{p} 2, \mathrm{q} 2) \mathrm{C}$-bands. There was a rather thick proximal C-band (q2) on the long arm of the sbM. Four C-bands (q2, q4, q6, q8) were observed at the proximal region of the long arm of the 1A.. These bands represented a concentration of very small $\mathrm{C}$-banding positive dots. The sA had two C-bands (q1, q3) on the long arm and one (p2) on the short arm.

3. P. delavayi Franchet: $[\mathrm{DE}]: 2 \mathrm{n}=2(\mathrm{lM}+\mathrm{mM}+\mathrm{sM}+1 \mathrm{~A}+\mathrm{sA})+1 \mathrm{~B}$

There was one proximal C-band (pl) on the short arm of the IM. The $\mathrm{mM}$ had a terminal band (p5) and two proximal bands (p1, p3) on the short arm, and a nearly-terminal band (q2) on the long arm. The sbM had a thick terminal band (p4) and a thin interstitial band (p2) on the short arm, and a nearly-terminal band on the long arm. A thick interstitial band (q2) was observed on the long arm of the $1 \mathrm{~A}$, while the long arm of the sA carried two thin interstitial bands (q2, q4). The average length of an acrocentric supernumerary chromosome, $B$, was $6.2 \mu \mathrm{m}$, and C-banding positive telomeric dots were detected in both arms.

4. P. polyphylla Smith var. polyphylla: $[\mathrm{PO}]: 2 \mathrm{n}=2(\mathrm{lM}+\mathrm{mM}+\mathrm{sM}+1 \mathrm{~A}+\mathrm{sA})+1 \mathrm{~B}$

The IM had a terminal band on each arm (p2, q4) and an interstitial band (q2) on the long arm. There were a terminal band (q4) and an interstitial band (q2) on the long arm of both $\mathrm{mM}$ and $\mathrm{sM}$ chromosomes. In addition, the $\mathrm{sM}$ had a proximal band ( $\mathrm{p} 1)$ on the short arm. There were an interstitial (q2) and a terminal band (q4) on the long arm of IA. The entire short arm of the sA was C-banding positive, and two interstitial (q2, q4) and one terminal band (q6) were observed on the long arm of the $\mathrm{sA}$. The B was a metacentric chromosome with an average length of $5.9 \mu \mathrm{m}$.

5. P. polyphylla Smith var. stenophylla Franchet: [ST]: $2 \mathrm{n}=2(\mathrm{lM}+\mathrm{mM}+\mathrm{sM}+\mathrm{lA}+\mathrm{sA})$

The $1 \mathrm{M}$ had a terminal band (p2) on the short arm and an interstitial one (q2) on the long arm. The $m M$ had a terminal band on either $\operatorname{arm}(p 5, q 2)$ and two proximal $(p 1, p 3)$ on the short arm. A terminal (p3, q4) and a proximal band (p1, q2) were observed on both arms alike of the sM. The $1 \mathrm{~A}$ had two terminal bands (p2, q4) and an interstitial band (q2). The sA carried two terminal bands (p2, q5) and one proximal (q1) and one interstitial band on its long $\operatorname{arm}(\mathrm{q} 3)$.

6. P. polyphylla Smith var. stenophylla Franchet f. latifolia (Wang et Chang) H. Li: [LA]: $2 \mathrm{n}=2(\mathrm{lM}+\mathrm{mM}+\mathrm{sM}+\mathrm{IA}+\mathrm{sA})$

On both arms of all metacentric chromosomes, i. e., IM, mM and $\mathrm{sM}$, the terminal bands were observed. Proximal bands were found in the IM (q1), sM (p2, p4), 1A (q2) and sA (q1). The entire short arm of the sA was $\mathrm{C}$-banding positive. A thick interstitial band was observed on the long arm of the mM.

7. P. polyphylla Smith var. yunnanensis (Franchet) Handel-Mazzetti: $[\mathrm{YU}]: 2 \mathrm{n}=2(\mathrm{M}+\mathrm{mM}+$ $\mathrm{sM}+\mathrm{IA}+\mathrm{sA}$ )

There was a terminal band (p2) on the short arm and an interstitial band (q2) on the long arm of the $1 \mathrm{M}$. In the $\mathrm{mM}$ each arm showed a terminal band (p4, $\mathrm{q} 2)$ and a thin proximal band was observed on the short arm. The sM had a terminal band on the short arm (p2) 
and a proximal band on the long arm (q2). Two proximal bands on the long arm (q2, q4) were observed in both $1 \mathrm{~A}$ and $\mathrm{sA}$. Moreover, $1 \mathrm{~A}$ had a terminal band (q6) on its long arm. 8. P. polyphylla Smith var. pseudothibetica $\mathrm{H}$. Li f. macrocepala $\mathrm{H}$. Li: [PS]: $2 \mathrm{n}=2$ (lM+ $\mathrm{mM}+\mathrm{sbM}+1 \mathrm{~A}+\mathrm{sA}$ )

The IM had a very proximal band on the short arm (p1) and two interstitial bands ( $q 2$, $\mathrm{q} 4)$ on the long arm. In the mM, a terminal band was observed on each arm (p5, q2), and a

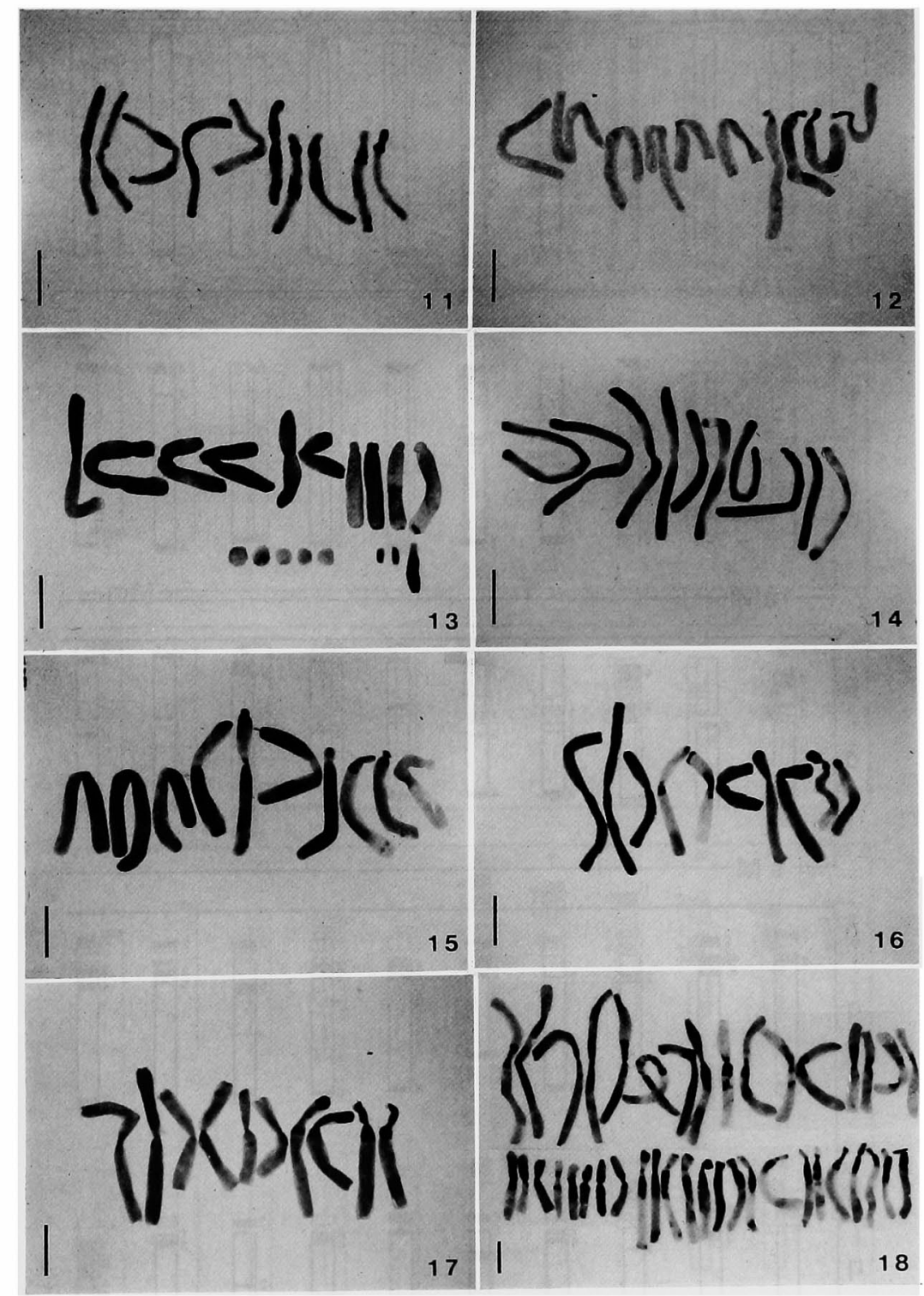

Figs. 11-18. 11, P. fragesii 12, P. thibetica $13, P$. axialis $14, P$. forrestii $15, P$. verticillata $17, P$. P. tetraphylla 18, P. japonica.

very proximal (p1) and an interstitial band (p3) were also detected. One thick and one thin terminal band was observed on each arm $(\mathrm{p} 3, \mathrm{q})$ ) of the sbM, which also carried a proximal band on its short arm (p1), and two interstitial bands on its long arm. The terminal regions (p2) of the short arms of both $1 \mathrm{~A}$ and sA were C-banding positive. Two interstitial bands 
q2, q4) were also observed in these acrocentric chromosomes. In addition, the long arm of the A had a terminal band (q6).

. P. mairei Leveille: [MA]: $2 \mathrm{n}=2(\mathrm{IM}+\mathrm{mM}+\mathrm{sM}+1 \mathrm{~A}+\mathrm{sA})$

The terminal region of all chromosomes had a conspicuous thick band except on the hort arm of the sA. A very thin interstitial band (p2) was observed on the short arm of the
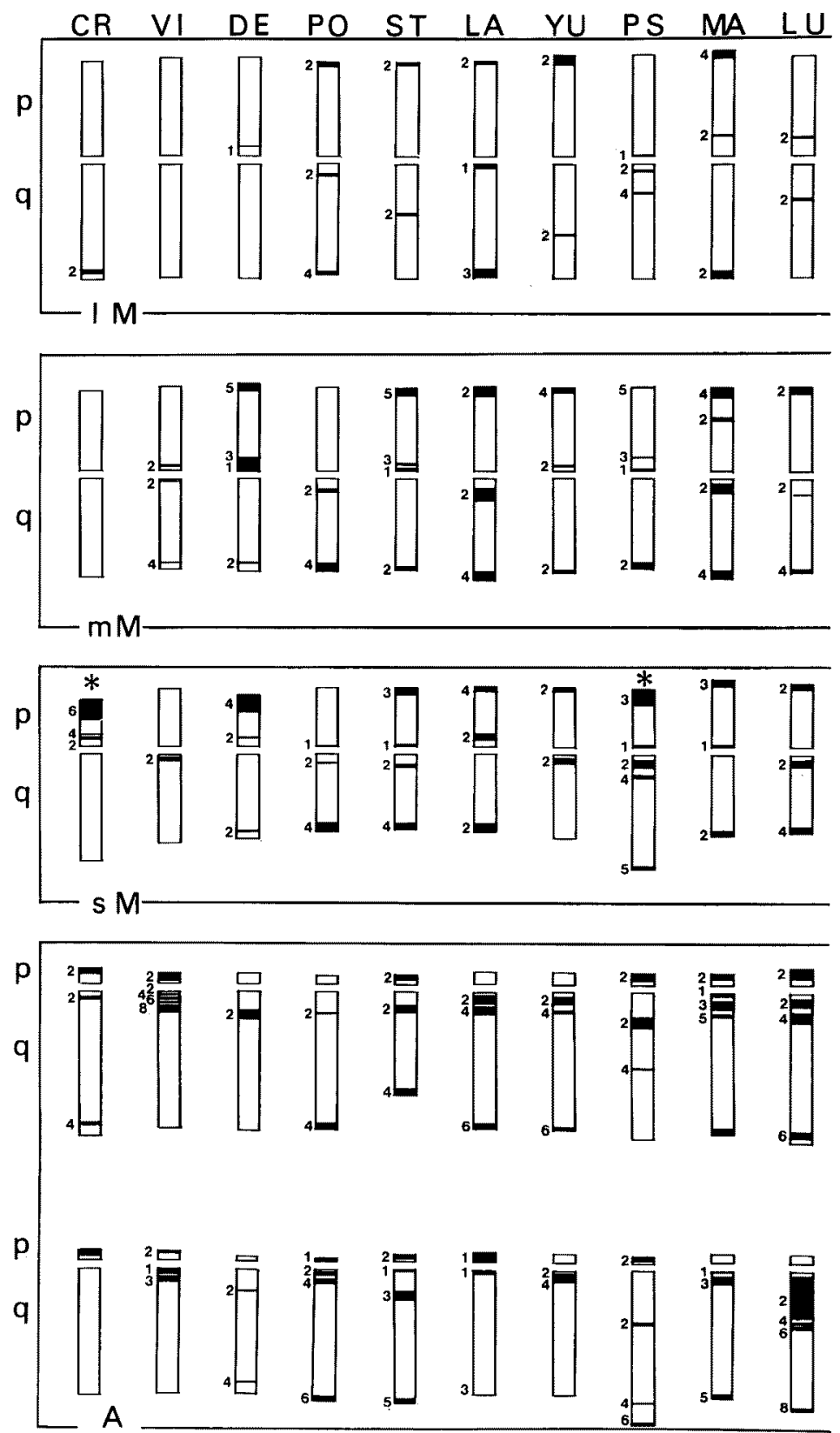

Fig. 19. Accurate idiograms showing C-banding patterns in 18 taxa examined. Abbreviations $\mathrm{p}, \mathrm{q}, \mathrm{IM}, \mathrm{mM}, \mathrm{sM}$, and $\mathrm{A}$ represent short arm, long arm, large metacentrics, medium size metacentrics, small metacentrics, and acrocentrics, respectively. CR, VI, DE and so on are the taxon codes (cf. Table 1). Asterisk indicates submetacentric chromosome, sbM. Continued next page. 
$1 \mathrm{M}$ and a rather thick interstitial one was observed on each arm of the $\mathrm{mM}(\mathrm{p} 2, \mathrm{q} 2)$. Nearly centromeric bands were found in the $s M(\mathrm{pl})$ and the sA (ql). The lA had two interstitial bands (q3, q5) and the sA one (q3).

10. P. luquanensis $\mathrm{H}$. Li: [LU]: $2 \mathrm{n}=2(\mathrm{IM}+\mathrm{mM}+\mathrm{sM}+\mathrm{IA}+\mathrm{sA})$

An interstitial band was observed on either arm of the $1 \mathrm{M}$. The $1 \mathrm{Mq} 2$ was thicker than
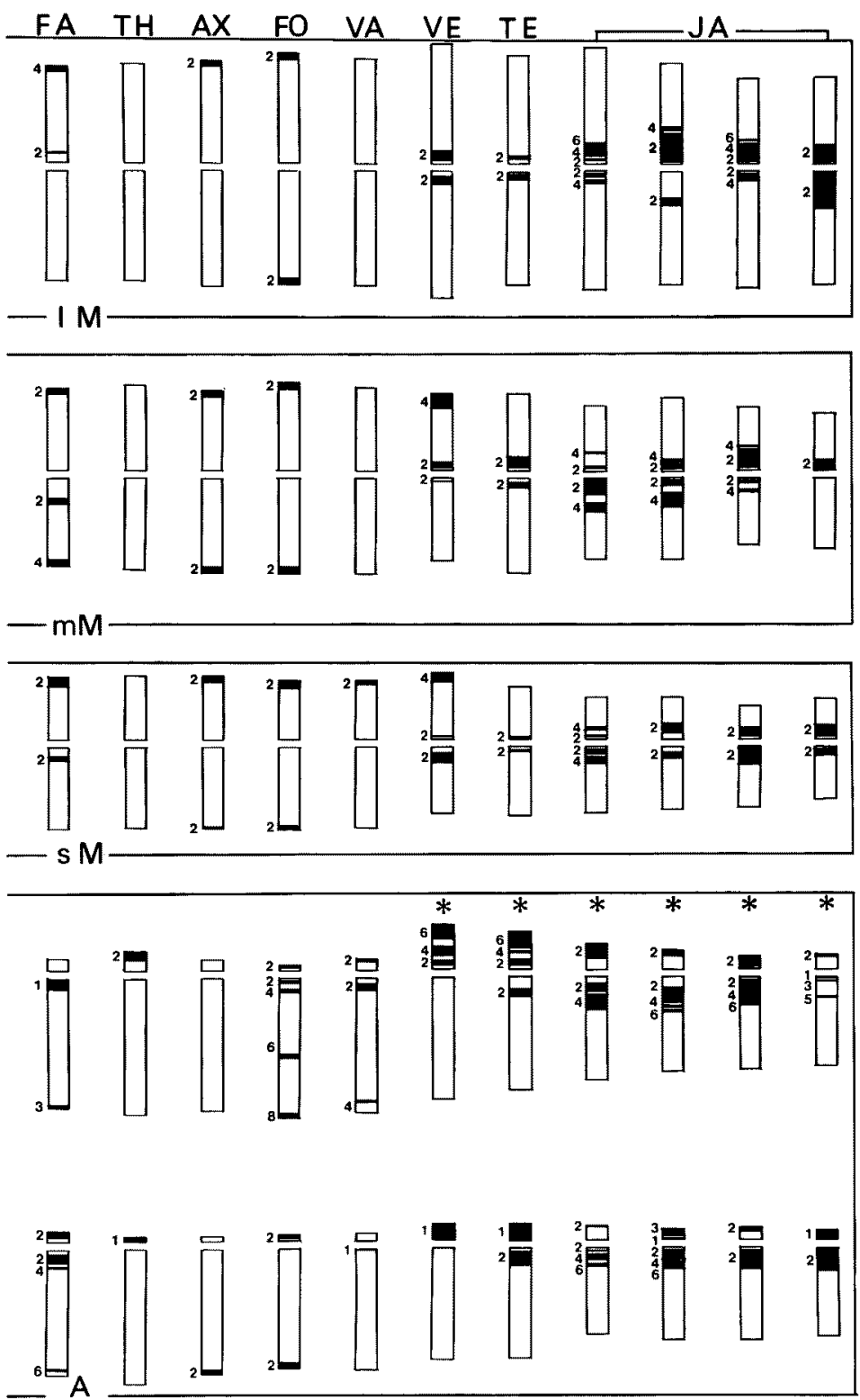
the $1 \mathrm{Mp} 2$. The banding patterns of the $\mathrm{mM}$ and the $\mathrm{sM}$ were very similar. These carried a terminal band on each arm (p2, q4) and one interstitial band (q2), but the sMq2 was thicker than the mMq2. Four conspicuous C-bands were observed in the 1A: one terminal (p2), two proximal (q2, q4) and one distal (q6). On the long arm of the sA, four bands were observed. The sMq2 was the largest heterochromatin block among all genomes examined in this study. The length of this block was $5.2 \mu \mathrm{m}$.

11. P. fargesii Franchet: $[\mathrm{FA}]: 2 \mathrm{n}=2(\mathrm{lM}+\mathrm{mM}+\mathrm{sM}+\mathrm{lA}+\mathrm{sA})$

One terminal and one proximal band were observed on the short arm of the IM. The $\mathrm{mM}$ carried a terminal band on each arm (p2, q4) and an interstitial band on the long arm (q2), and all were fairly conspicuous. The $s M$ had one terminal (p2) and one thick interstitial band (q2). On the long arm of the $1 \mathrm{~A}$, one nearly centromeric band (q1) and one terminal band (q3) were observed. The sA carried four bands: one terminal (p2), two proximal (q2, q4) and one distal (q6).

12. P. thibetica Franchet: $[\mathrm{TH}]: 2 \mathrm{n}=2(\mathrm{lM}+\mathrm{mM}+\mathrm{sM}+\mathrm{lA}+\mathrm{sA})$

The C-band was observed only on the short arm of the acrocentric chromosomes. These were 1Ap2 and sAp1. Therefore this species contained the smallest amount of heterochromatin among all taxa we examined.

13. P. axialis $\mathrm{H} . \mathrm{Li}:[\mathrm{AX}]: 2 \mathrm{n}=2(\mathrm{MM}+\mathrm{mM}+\mathrm{sM}+1 \mathrm{~A}+\mathrm{sA}+3 \mathrm{~B}$ or $5 \mathrm{~B})$

The short arms of $1 \mathrm{M}, \mathrm{mM}$ and $\mathrm{sM}$ carried one thick terminal band each (p2), and the long arms of $\mathrm{mM}, \mathrm{sM}$ and $\mathrm{sA}$ each had a terminal band (q2), too. Five C-banding negative B chromosomes of the same size were found in one plant specimen. The length of these Bs was $2.9 \mu \mathrm{m}$. Another plant carried three Bs. The length of one B was $8.2 \mu \mathrm{m}$ while that of the rest was $1.8 \mu \mathrm{m}$. The longer B was telocentric and C-banding positive.

14. P. forrestii (Takhtajan) $\mathrm{H}$. Li: $[\mathrm{FO}]: 2 \mathrm{n}=2(\mathrm{lM}+\mathrm{mM}+\mathrm{sM}+\mathrm{lA}+\mathrm{sA})$

There was a terminal band (p2, q2) on each arm of all metacentric chromosomes. All acrocentrics also carried terminal bands (p2, q2, q8). An interstitial band was observed only in the long arm of the 1A. These were also two proximal bands (q2, q4) and one middle band (q6).

15. P. vaniotii Leveille: [VA]: $2 \mathrm{n}=2(\mathrm{lM}+\mathrm{mM}+\mathrm{sM}+1 \mathrm{~A}+\mathrm{sA})$

Among three metacentric chromosomes, only one band at the terminal (p2) was observed in the sM. Terminal bands on both arms (p2, q4) and one proximal band (q2) were found in the $1 \mathrm{~A}$. A very thin, nearly centromeric band was observed in the $\mathrm{sA}$.

16. P. verticillata M.-Bieberstein: $[\mathrm{VE}]: 2 \mathrm{n}=2(\mathrm{IM}+\mathrm{mM}+\mathrm{s} \mathrm{M}+\mathrm{sbM}+\mathrm{A})$

There were interstitial proximal bands $(\mathrm{p} 2, \mathrm{q} 2)$ on both arms of all metacentric chromosomes. A terminal band was observed on the short arm of the mM. In the short arm of the $\mathrm{sbM}$, a large conspicuous terminal band (p6) and two interstitial bands (p2, p4) were detected. The entire short arm of the sA was C-banding positive. The interstitial band in each chromosome was not species-specific, but individual-specific. However, the mMp4, sMp4, sbMp6 and sApl were species-specific bands. Details of intraspecific variation of the banding pattern of this species was already reported by Miyamoto et al. (1991).

17. P. teraphylla A. Gray: $[\mathrm{TE}]: 2 \mathrm{n}=2(\mathrm{IM}+\mathrm{mM}+\mathrm{sM}+\mathrm{sbM}+\mathrm{A})$

Interstitial bands (p2, q2) appeared at the proximal regions of all metacentric chromosomes. The sbM had four C-bands: one conspicuous terminal (p6), two interstitial (p2, p4) and one thick interstitial (q2). The entire short arm of the sA was C-banding positive. The proximal band on the long arm of the $s A$ was conspicuous. With the exception of $s A q 2$, the interstitial bands of this species were not species-specific, but rather individual-specific. Only three bands, sbMp6, sAp1 and sAq2, were species-specific, as was already reported by Miyamoto and Kurita (1990). 
18. P. japonica (Feanchet et Savatier) Franchet: [JA]: $2 n=4(\mathrm{IM}+\mathrm{mM}+\mathrm{sM}+\mathrm{sbM}+\mathrm{A})$

Twenty-five plants of $P$. japonica from three populations were analyzed. Of all the taxa examined, the C-banding patterns of this species were most complicated, and considerable intraspecific variation in pattern was observed. In fact, patterns differed from population to population and in some instances at individual level (details will be reported in elsewhere). Therefore the C-banded idiogram of a plant shown in Fig. 2 (18) is only representative. With the exception of one $\mathrm{mM}$ which carried a proximal band on its short arm, a considerable amount of C-banding positive hetrochromatin was observed at the proximal region of each arm of all metacentric chromosomes. No terminal band was detected among those metacentrics. The terminal band on the short arms and the proximal interstitial band on the long arms of all sbM and A type chromosomes were observed. Fundamentally very similar patterns were observed in all plants examined. The proportion of $\mathrm{C}$-banding positive heterochromatin volume to total chromatin of the plant represented is 18.8 to 100 . This rate $(18.8 \%)$ is the highest shown by any taxa examined.

\section{Discussion}

The genus Paris consists of nineteen species with several infraspecific taxa (Li 1986). Their basic karyotypes as studied with conventional nondifferential staining methods such as the aceto-orcein squash method had been divided into two groups (Hong and Zhu 1987, $\mathrm{Li}$ et al. 1988). One consists of three metacentric and two acrocentric chromosomes. The other cosists of three metacentric, one submetacentric and one acrocentric chromosome. Taxa of the former karyotype are distributed in temperate zones, with the exception of one subtropic species, $P$. bashanensis. Those of the latter type are found in the tropics or subtropics. Within each group, however, it is very difficult to distinguish the karyotype of one species from that of the others, because they bear a close resemblance to the others. A differential staining method, C-banding, overcame this difficult situation (Miyamoto et al. 1991). So we analyzed the C-banded karyotypes of eighteen taxa and compared them in order to clarify the differences among them. Then we tried to find some relationships between C-banding patterns and systematic position.

With the exceptions of $P$. japonica, $P$. tetraphylla and $P$. verticillata, which are distributed in Japan, we were able to examine only from one to three individuals in each taxon. It is very difficult to obtain many living plants in China, where the Paris species are standing on the brink of extinction. Strictly speaking, therefore, we were unable to determine which bands consistently appear in the Chinese taxa.

In $P$. tetraphylla, the sbMp6, Ap1 and Aq2 appeared consistently in all plants examined, and the $1 \mathrm{Mp} 2,1 \mathrm{Mq} 2, \mathrm{mMp} 2, \mathrm{mMq} 2, \mathrm{sbMp} 2$ and sbMq2 were observed in many plants. In $P$. verticillata, the $\mathrm{mMp4}, \mathrm{sMp} 4, \mathrm{sbMp} 6$ and $\mathrm{Apl}$ appeared constantly in all plants examined, and the $1 \mathrm{Mq} 2, \mathrm{mMp} 2, \mathrm{mMq} 2$ and sMq2 appeared in the majority of plants examined (Miyamoto et al. 1991). Bands which appeared constantly or dominantly were without exception the thick ones. On the basis of this data we tentatively deduced that the thick bands observed in every taxon represent the constant or dominant ones in each taxon. The following discussion is based upon this hypothesis.

Each species examined has a unique and matchless C-banding pattern, and we were unable to detect any distinction between the "tropical" and the "temperate" karyotypes. However, we did observe some similarities between or among species.

Somewhat complicated infraspecific variations were observed in $P$. polyphylla. We examined five infraspecific taxa. All taxa showed unique banding patterns, with that or $P$. polyphylla var. pseudothibetica f. macrosepala being the most conspicuous. The genome of 
this taxon included a sbM instead of the sM observed if the other four taxa. Two A type chromosomes having a rather high arm ratio and the thick $\mathrm{C}$-band Aq2 situated midway on the long arm were also characteristic of this taxon. Moreover, no terminal band was detected in the $1 \mathrm{M}$ of this taxon. The $\mathrm{M}$ type chromosomes of $P$. polyphylla var. stenophylla and var. yunanensis showed similar banding patterns, but the patterns of their As differed. The 1A of $P$. polyphylla var. yunnanensis and var. stenophylla f. latifolia showed the same banding pattern. Miyamoto and Kurita (1990) studied the C-banding patterns of four forma of $\boldsymbol{P}$. tetraphylla, and found no remarkable differences among them. Therefore the degree of speciation in $P$. polyphylla may be greater than that in $P$. teraphylla.

Although it has the highest chromosome number in the genus Paris, $2 \mathrm{n}=40, P$. japonica's chromosomes can be classified into five groups according to arm ratios as shown in Fig. 2 (18). Therefore this is an octoploid species (Haga 1934). However, the C-banding pattern of every chromosome in each group has slight differences. So this plant may not be a simple autopolyploid. In general, however, the $M$ type chromosomes showed similar banding patterns. Namely they carried proximal interstitial bands on both arms with the exception of the shortest $\mathrm{mM}$. This is somewhat similar to the patterns of $\boldsymbol{P}$. tetraphylla and $\boldsymbol{P}$. verticillata, though there was a terminal band on the short arm of the $\mathrm{mM}$ and $\mathrm{sM}$ of $P$. verticillata. The pattern of the shortest A was the same as that of the sA in P. tetraphylla.

Opinions vary as to the systematic position of $P$. japonica. For example, Tatewaki and Suto (1935) treated this as a monotypic genus, Kinugasa, because the gross morphology is intermediate between the typical Paris and a related genus Trillium. The basic karyotype of this species, however, corresponds to that of the typical Paris species. Namely the A type chromosome of this species carries a conspicuous satellite which is not observed in the genomes of Trillium (Haga 1934). On the other hand, the cold-induced H-segment patterns or Cbanding patterns of some Trillium species are known (Darlington and La Cour 1940, Fukuda 1973, Chinnappa and Morton 1978). It has been reported that the H-segments of Paris and Trillium positively react to the C-banding method in most cases (Utsumi and Takehisa 1974, Miyamoto and Kurita 1990). So the H-segment patterns can be regarded as equivalent to the $\mathrm{C}$-banding pattern in this case. Most Trillium species have a large $\mathrm{C}$-band or $\mathrm{H}$-segment on the short arm of the $\mathrm{mM}$ and/or sM. In the genomes of $P$. japonica, we did not note the $\mathrm{mM}$ and $\mathrm{sM}$ to have such a banding pattern, but the pattern of the $1 \mathrm{M}$ is fairly similar to that of $T$. erectum. The banding patterns of the sbM and A type chromosomes of $P$. japonica were unique and matchless, but some showed similarities to the patterns of the sbM and $A$ of $P$. tetraphylla, $P$. vietnamense, $P$. polyphylla var. yunnanensis, $T$. erectum, $T$. grandiflorum and $T$. kamtschaticum. These observations suggest that $P$. japonica may have a common ancestor with the species of Trillium and typical Paris.

The proportion of C-banding positive heterochromatin to euchromatin in each taxon ranged from $1.8 \%$ in $P$. thibetica to $18.8 \%$ in $P$. japonica and the average was $8.4 \%$. Among the subgenus Paris (Li 1984), the average amount of the heterochromatin of the section Axiparis is $4.9 \%$, while that of the section Paris and Kinugasa is $11.0 \%$ and $18.8 \%$, respectively. The distribution of the former is restricted to northern Yunnan. P. thibetica which has the least heterochromatin amount in the subgenus Daiswa ( $\mathrm{Li} \mathrm{1984)}$ is very distinct in its gross morphology.

\section{Summary}

The C-banding patterns of 18 taxa of the genus Paris were analyzed with the chromosome image analyzing system, CHIAS. Each species examined had a unique and matchless Cbanding pattern (Figs. 1, 2). Among them, $P$. japonica, a presumptive relict to the Ice 
Age, showed the most complicated pattern and had the highest proportion of C-banding positive heterochromatin to euchromatin in its genomes. $P$. thibetica, a Tibetan species, showed the simplest pattern and the lowest proportion of heterochromatin to euchromatin. Despite the uniqueness of each species, we were able to recognize certain similarities between and/or among species. The metacentric chromosomes of $P$. polyphylla var. stenophylla and $P$. polyphylla var. yunnanesis showed similar banding patterns. Proximal bands were observed on both arms of the metacentric chromosomes in three Japanese species, $P$. japonica, $P$. tetraphylla and $P$. verticillata. On the other hand, we were unable to make any distinction of the C-banding patterns of "tropical" and the "temperate" karyotypes.

\section{Acknowledgment}

We are deeply indebted to Dr. Kiichi Fukui of the Hokuriku National Agricultural Experiment Station for his considerable assistance of the adaption of the CHIAS which he orginally constructed. We wish to thank Dr. Ching I. Peng and Dr. Hiromasa Izumi for supplying of plants of $P$. polyphylla var. polyphylla. This work was supported in part by a Grant-inAid for International Scientific Research Program (Joint Research, No. 02044028) and by another for Specified Research provided by the Ministry of Education, Science and Culture of Japan.

\section{References}

Chinnapa, C. C. and Morton, J. K. 1978. Heterochromatic banding patterns in two species of Trillium. Can. J. Genet. Cytol. 20 : 475-481.

Darlington, C. C. 1941 . Polyploidy, crossing-over, and heterochromatin in Paris. Ann. Bot. N.S. 5: 203-216.

— and La Cour, L. 1938. Deferential reactivity of the chromosomes. Ann. Bot. N.S. 2: 615-625.

- and - 1940. Nucleic acid starvation of chromosomes in Trillium. J. Genetics, 40: 185-213.

Fukuda, I. 1973. Comparative study of chromosome variation in the Japanese and American Trillium species. Sci. Rep. Tokyo Women's Christian College. 29-31: 361-367.

Geitler, L. 1938. Weitere cytogenetische Untersuchungen an naturichen Populationen von Paris quadrifolia. Zeitschr. Indukt. Abstamm. u. Vererbuglehre 75: 161-190.

Gotoh, K. 1933. Karyologische Studien an Paris und Trillium. Jap. J. Genet. 8: 197-203.

- 1937. Studies on the chromosome number in Paridae. Jap. J. Genet. 13: 209-210.

Gu, Z. 1984. Karyotype analysis of two new species on Paris L. Acta Bot. Yunnan 6: 464-470.

- and Na, H. 1986. Karyotype studies in eight taxa of Paris L. Acta Bot. Yunnan 8: 315-318.

- and Li, H. 1988. Cytotaxonomic study on the genus Paris. Acta Bot. Yunnan 10: 125-137.

Haga, T. 1934. The comparative morphology of the chromosome complement in the tribe Parideae. J. Fac. Sci. Hokkaido Imperial Univ. Ser. V, 3: 1-32.

- 1942. Geographycal distribution of Trilliaceae plants in relation of polyploidy. Jap. J. Genet. 18: 168-171.

Hara, H. 1969. Variation in Paris polyphylla Smith with reference to other Asiatic species. J. Fac. Sci. Univ. Tokyo, Sect. III, 10 : 141-180.

Hong, D. and Zhu, X. 1987. Cytotaxonomical studies on Liliaceae (s.l.) (1) Report on karyotypes of 10 species of 6 genera. Acta Phytoyarx. Sinica 25: 245-253.

Kayano, H. 1961. Mitotic lagging of B-chromosomes in Paris tetraphylla. CIS 2: 7.

Kurabayashi, M. 1952. Differential reactivity of the specific chromosome segments in Paris. J. Fac. Sci. Hokkaido Univ. Ser. V, 6: 1991-209.

- and Samejima, J. 1953. Chromosomal changes observed in natural populations of Paris tetraphylla A. Gray. Cytologia 18: 176-149.

Laane, M. M. and Lie, T. 1985. Fremstilling av kromosompreparater med enkle metoder. Blyttia 1985: $7-15$.

Lavrenko, A. N. and Serditov, N. P. 1987. Chromosome numbers in some members of the Urals flora. Bot. Zurn. 72: 846-847.

Li, H. 1986. A study of the taxonomy of the genus Paris L. Bull. Bot. Res. 6: 109-149.

-, Gu, Z. and Na, H. 1988. Cytogeographic study of the genus Paris. Acta Phytotax. Sinica 26: 1-10. 
Löve, A. and Löve, D. 1944. Cytotaxonomical studies on boreal plants. III Some new chromosome numbers of Scandinavian plants. Arkiv. Bot. 31A 12: 1-22.

Malakhova, L. A., Voronova, L. O. and Kozlova, A. A. 1979. Chromosome numbers of some species of the flora of Siberian Lime-forest. Chmavaja Taiga i Problema. Reliktov. Tomsk. pp. 47-51.

Mitchell, B. 1987. Paris part 1. The Plantsman 9: 81-89.

- 1988. Paris part 2. Daiswa. The Plantsman 10: 167-190.

Miyamoto, J. and Kurita, S. 1990. C-band polymorphism in the karyotype of Paris tetraphylla. Cytologia 55: 301-313.

-, -, and Fukui, K. 1991. Image analysis of C-banding patterns in two herbs: Paris tetraphylla A. Gray and $P$. verticillata M. v Bieb. (Liliaceae). Jpn. J. Genet. 66: 335-345.

Noda, S. 1963. Karyotype and differential reaction in Paris tetraphylla. CIS. 4: 6.

Pólya, L. 1950. Chromosome numbers of Hungarial plants II. Ann. Biol. Univ. Debreceniensis 1: 46-56.

Skaliñska, M., Banach-Pogan, E. and Wcislo, H. 1957. Further studies in chromosome numbers of Polish Angiosperms. Acta Soc. Bot. Polon. 26: 215-245.

Sorsa, V. 1962. Chromosomenzahlen Finnischer Kormophyten 1. Ann. Acad. Sci. Fennica. Ser. A. IV. 58: 1-14.

Stow, I. 1935. On the correlation between the satellite of chromosome and the leaf shape in Parideae from Hokkaido. J. Fac. Sci. Hokkaido Imperial Univ. Ser. V. 5: 31-46.

Suzuki, M. and Yoshimura, N. 1986. A study of the chromosome number and karyotype of Paris tetraphylla A. Gray. Ann. Rep. Fac. Educ. Ibaraki Univ. 35: 33-43.

Takhtajan, A. 1983. A revision of Daiswa. Brittonia 35: 255-270.

Tatewaki, M. and Suto, T. 1935 . On the new genus Kinugasa. Trans. Sapporo Nat. Hist. Soc. 14: 34-37.

Tischler, G. 1934. Die Bedeutungen der Polyploidie fur die Verbreitung der Angiospermen erlautert an den Arten Schleswig-Holsteins, mit Ausblicken auf andere Florengebiete. Bot. Jahrb. 67: 1-36.

Utsumi, S. and Takehisa, S. 1974. Heterochromatin differentiation in Trillium kamtschaticum by ammoniacal silver reaction. Exper. Cell Res. 86: 398-401. 